(c) American Dairy Science Association, 2004.

\title{
Factors Affecting Incorrect Paternity Assignment in the Israeli Holstein Population
}

\author{
J. I. Weller, ${ }^{1}$ E. Feldmesser, ${ }^{1}$ M. Golik, ${ }^{1}$ I. Tager-Cohen, ${ }^{1}$ \\ R. Domochovsky, ${ }^{1}$ O. Alus, ${ }^{1}$ E. Ezra, ${ }^{2}$ and M. Ron ${ }^{1}$ \\ ${ }^{1}$ Institute of Animal Sciences ARO, The Volcani Center, Bet Dagan 50250, Israel \\ ${ }^{2}$ Israel Cattle Breeders Association, Caesaria Industrial Park, Caesaria 38900, Israel
}

\begin{abstract}
A total of 6040 Israeli Holstein cows from 181 Kibbutz herds listed as progeny of 11 sires were genotyped for 104 microsatellites. Seventeen markers were deleted due to a frequency of erroneous genotypes $>1 \%$, leaving 160,470 valid genotypes. Conflicts between the putative sire and daughter in at least 2 markers and for at least $10 \%$ of the markers genotyped per cow were required to reject paternity. Cows that did not meet the requirements for paternity confirmation or rejection were deleted from further analysis. The frequency of rejected paternity was $11.7 \%$. The effects of recorded sire, birth year, geographical region, herd, and inseminator on the frequency of paternity rejection were analyzed with linear and nonlinear models. Only the effects of inseminator and recorded sire were significant in all models tested that included these effects. The main causes of incorrect paternity recording appear to be inseminator recording mistakes, and possibly mistakes with respect to semen labeling at the AI institutes. Incorrect paternity recording due to multiple inseminations by different sires could explain, at most, $20 \%$ of the paternity mistakes. Instituting a system of quality control, especially at the level of the inseminator, should reduce paternity errors to no more than $8 \%$, and increase genetic progress by at least $1 \%$.
\end{abstract}

(Key words: paternity error, DNA microsatellites, dairy cattle, Israeli Holstein)

Abbreviation key: Ex = exclusion probability, ISAG = International Society of Animal Genetics.

\section{INTRODUCTION}

Correct pedigree information is paramount in a successful breeding program and its importance has increased with the introduction in 1990 of individual animal models for national genetic evaluations. Even

Received December 21, 2003.

Accepted March 29, 2004.

Corresponding author: J. I. Weller; e-mail: weller@agri.huji.ac.il. though pedigree assignments are generally not questioned, several studies have shown that the proportion of errors in sire identification varies from a few percent to as much as $22 \%$ (Christensen et al., 1982; Geldermann et al., 1986; Bovenhuis and van Arendonk, 1991; Ron et al., 1996; Visscher et al., 2002). These mistakes reduce the rate of genetic progress (Van Vleck, 1970a,b; Israel and Weller, 2000; Banos et al., 2001; Visscher et al., 2002).

Christensen et al. (1982) give the following reasons for errors in paternity recording: 1) mistakes by AI institutes in labeling semen; 2) AI technicians incorrectly identifying semen samples; 3 ) the insemination of cows already pregnant by a previous insemination; 4) errors when the bull's herdbook number or name is entered into the insemination record; 5) the use of natural-service bulls leading to pregnancies of previously inseminated cows which were assumed to be pregnant from the AI bull; 6) mistakes in sire identification when a cow enters the milking herd in schemes where pedigree information on milk recorded cows is obtained through the milk recording program; and 7) interchange of calves at the farm. In the Israeli Holstein population, points 5 and 6 are not relevant, because natural-service bulls are not used, and information on pedigree is not obtained through the milk-recording program.

Most previous studies that estimated the frequency of incorrect paternity were based on the analysis of, at most, several hundred cows (Ron et al., 1996; Visscher et al., 2002), and the number of animals with incorrect paternity was $>100$. There were only minimal attempts to analyze these samples to determine which factors were most responsible for pedigree errors (e.g., Visscher et al., 2002, compared misidentification rates in DNA derived from blood and hair samples).

Traditionally, pedigree verification in dairy cattle has been carried out using blood groups and protein polymorphisms (Stormont, 1967). Now, DNA microsatellites are the international standard system of identity verification in livestock (Bredbacka and Koskinen, 1999) and have 2 main advantages over traditional blood typing. Any sample from an individual containing 
DNA can be used; hence, sampling techniques can be noninvasive and retrospective from stored tissue or semen samples. For example, Ron et al. (2003) developed and tested a method to sample cows using vaginal swabs. In addition, the accuracy is much greater than for blood group markers because microsatellites are generally polyallelic, and a virtually unlimited reservoir of markers is available (e.g., Kappes et al., 1997).

We have recently completed a complete genome scan of the Israeli Holstein population for QTL affecting economic traits by the daughter design (Weller et al., 1990; Ron et al., 2004). Eleven sire families with 6040 putative daughters were genotyped for 104 microsatellites. As a by-product of this study, paternity as listed in the herdbook could be verified or rejected for nearly all cows genotyped.

The objectives of this study were 1) to estimate the frequency of paternity misidentifications in the IsraeliHolstein population using the data collected for the genome scan, and 2) to determine the relative contributions of the factors listed by Christensen et al. (1982) to these mistakes.

\section{MATERIALS AND METHODS}

\section{Population Analyzed and Determination of Paternity in the Herdbook}

A total of 6040 cows from 181 Kibbutz (communal) herds were genotyped. Paternity was determined by the Israeli herdbook for all cows. These cows were listed as progeny of 11 sires. All but 2 cows were born between 1990 and 1997. All matings of herdbook-recorded cows were by AI, and all inseminations at Kibbutz herds were recorded.

The following algorithm determined paternity in the Israeli herdbook database: if there were a single insemination between 265 and $290 \mathrm{~d}$ prior to calving and the nearest insemination was at least $12 \mathrm{~d}$ distant, then this insemination was recorded as the effective insemination, the service sire was recorded as the sire of the calf, and gestation length was computed as calving date minus insemination date. If there were more than one insemination during this period or there was a 2nd insemination within $12 \mathrm{~d}$, gestation length was not computed. If the multiple inseminations during this period were from the same sire, then this sire was recorded as the sire of calf. If the inseminations were from more than a single sire, paternity was listed as unknown.

If no inseminations were recorded between 265 and $290 \mathrm{~d}$ prior to partuition, but there was at least one insemination between 240 and $265 \mathrm{~d}$ prior to calving, the farmer was contacted, and the calf was appraised. If the farmer confirmed that a premature birth was likely, the earliest insemination during this period was listed as the effective insemination, and paternity and gestation length were recorded accordingly. If there were no insemination between 240 and $290 \mathrm{~d}$ prior to calving, but there was an insemination between 290 and $300 \mathrm{~d}$ prior to calving, the farmer was contacted and the calf was appraised. If the farmer confirmed that a long gestation was likely, then this insemination was listed as the effective insemination and paternity and gestation length were recorded accordingly. If there were $<12 \mathrm{~d}$ between presumed effective insemination and the next or previous insemination, but both inseminations were from the same sire, then this sire was listed as the sire of calf, but gestation length was not recorded. If the 2 inseminations were from different sires, then paternity was listed as unknown. If no insemination was recorded between 240 and $300 \mathrm{~d}$ prior to calving, then paternity was listed as unknown and gestation length was not recorded.

\section{Genotyping Methods}

Genotyping methods have been described in detail by Ron et al. (2004). The 73 microsatellites were run in 6 panels. Each panel of microsatellites was based on 3 to 5 multiplexed PCR reactions of fluorescent-labeled microsatellites. Microsatellites were first chosen to obtain complete coverage of the bovine genome with a maximal spacing of $50 \mathrm{cM}$ between markers. Additional selection criteria were ease of scoring, mean heterozygosity, and appropriate fragment size relative to the other microsatellites included in each panel. Progeny of families with significant contrasts for specific markers were genotyped for additional markers linked to the markers with significant effects to perform interval mapping. In total, 104 markers were genotyped. The number of sires and cows genotyped per marker and the map locations of the markers genotyped, based on the Clay Center genetic map (http://sol.marc.usda.gov/ genome/cattle/cattle.html), are given in Table 1. Markers denoted with an asterisk are included in the International Society for Animal Genetics (ISAG) standard panel for pedigree confirmation (Bredbacka and Koskinen, 1999). Eight of the 11 markers included in the panel were genotyped in the current study. There were a total of 188,717 valid cow genotypes and 682 sire genotypes. Thus, the mean number of genotypes per marker was 1815 for cows and 6.6 for sires.

\section{Edits on Genotypes}

The rules of Mendelian inheritance require that each parent and progeny should share at least one common allele. Discrepancies between the cow and putative sire genotypes may be due to mutation, errors in genotyp- 
Table 1. Marker locations, number of sires and cows genotyped, single conflicts per marker, frequency of single conflicts, and deviations from expected heterozygote frequency.

\begin{tabular}{|c|c|c|c|c|c|c|c|}
\hline \multirow[b]{2}{*}{ Marker $^{1}$} & \multirow[b]{2}{*}{$\mathrm{BTA}^{2}$} & \multirow[b]{2}{*}{ Position $^{3}$} & \multicolumn{2}{|c|}{ Number of } & \multicolumn{2}{|c|}{ Single conflicts } & \multirow{2}{*}{$\begin{array}{l}\text { Heterozygosity } \\
\text { obs }-\mathrm{ex}^{4}\end{array}$} \\
\hline & & & Sires & Cows & Number & Frequency & \\
\hline BM4307 & 1 & 35.2 & 9 & 1868 & 11 & 0.006 & -0.03 \\
\hline INRA049 & 1 & 67.5 & 9 & 2221 & 13 & 0.006 & -0.04 \\
\hline BM1824* & 1 & 108.6 & 9 & 2353 & 1 & 0.000 & 0.00 \\
\hline ETH121 & 2 & 34.0 & 10 & 2255 & 1 & 0.000 & -0.00 \\
\hline BMS1126 & 2 & 56.0 & 10 & 3050 & 2 & 0.001 & 0.04 \\
\hline RMN041 & 2 & 69.0 & 3 & 1039 & 17 & 0.016 & 0.03 \\
\hline BMS1866 & 2 & 82.7 & 2 & 667 & 4 & 0.006 & -0.01 \\
\hline BMS1987 & 2 & 98.2 & 2 & 1093 & 4 & 0.004 & -0.18 \\
\hline BMS2519 & 2 & 101.5 & 3 & 1029 & 18 & 0.017 & -0.01 \\
\hline BM2113* & 2 & 106.2 & 9 & 2960 & 14 & 0.005 & 0.03 \\
\hline IDVGA37 & 2 & 108.2 & 1 & 670 & 1 & 0.001 & 0.03 \\
\hline IDVGA2 & 2 & 117.8 & 2 & 602 & 8 & 0.013 & -0.02 \\
\hline FCB11 & 2 & 120.4 & 3 & 1372 & 13 & 0.009 & 0.02 \\
\hline UWCA7 & 3 & 19.9 & 9 & 2513 & 35 & 0.014 & -0.19 \\
\hline INRA003 & 3 & 59.5 & 11 & 3122 & 1 & 0.000 & 0.06 \\
\hline HUJI177 & 3 & 87.4 & 10 & 2872 & 11 & 0.004 & -0.01 \\
\hline INRA200 & 3 & 109.7 & 8 & 2272 & 24 & 0.011 & -0.03 \\
\hline RM188 & 4 & 24.7 & 11 & 2952 & 5 & 0.002 & -0.00 \\
\hline BM6458 & 4 & 68.3 & 10 & 2309 & 24 & 0.010 & -0.03 \\
\hline BP1 & 5 & 19.0 & 10 & 2746 & 12 & 0.004 & -0.03 \\
\hline ETH10* & 5 & 70.0 & 9 & 2363 & 0 & 0.000 & 0.02 \\
\hline ILSTS93 & 6 & 0.0 & 3 & 1336 & 3 & 0.002 & 0.00 \\
\hline INRA133 & 6 & 8.2 & 2 & 711 & 4 & 0.006 & -0.17 \\
\hline ILSTS90 & 6 & 11.8 & 1 & 543 & 4 & 0.007 & 0.04 \\
\hline BMS1329 & 6 & 35.5 & 2 & 658 & 5 & 0.008 & 0.06 \\
\hline BMS2508 & 6 & 44.2 & 2 & 898 & 0 & 0.000 & -0.00 \\
\hline BM143 & 6 & 49.4 & 9 & 2633 & 1 & 0.000 & 0.01 \\
\hline BMS518 & 6 & 55.2 & 2 & 1113 & 0 & 0.000 & 0.01 \\
\hline BMS483 & 6 & 64.0 & 3 & 1051 & 0 & 0.000 & -0.02 \\
\hline BMS360 & 6 & 66.5 & 3 & 1308 & 10 & 0.008 & 0.09 \\
\hline BM415 & 6 & 76.3 & 9 & 2556 & 1 & 0.000 & -0.01 \\
\hline BM8124 & 6 & 94.2 & 1 & 573 & 2 & 0.003 & 0.09 \\
\hline BMS739 & 6 & 113.4 & 3 & 1282 & 2 & 0.002 & 0.02 \\
\hline BM7160 & 7 & 0.0 & 2 & 440 & 6 & 0.014 & 0.10 \\
\hline BMS713 & 7 & 15.2 & 2 & 421 & 2 & 0.005 & 0.01 \\
\hline RM006 & 7 & 22.1 & 7 & 2207 & 0 & 0.000 & 0.04 \\
\hline BM6105 & 7 & 35.7 & 1 & 423 & 4 & 0.009 & 0.15 \\
\hline TGLA303 & 7 & 38.5 & 1 & 439 & 1 & 0.002 & 0.08 \\
\hline BM7247 & 7 & 58.0 & 1 & 414 & 1 & 0.002 & 0.06 \\
\hline UWCA20 & 7 & 59.9 & 7 & 2550 & 5 & 0.002 & 0.02 \\
\hline BMS2840 & 7 & 64.3 & 1 & 322 & 0 & 0.000 & 0.13 \\
\hline INRA112 & 7 & 72.1 & 1 & 324 & 2 & 0.006 & 0.07 \\
\hline BMS792 & 7 & 76.9 & 1 & 343 & 0 & 0.000 & 0.03 \\
\hline BMS1331 & 7 & 91.1 & 1 & 336 & 0 & 0.000 & -0.00 \\
\hline ILSTS006 & 7 & 116.0 & 11 & 2852 & 2 & 0.001 & 0.03 \\
\hline BMS1591 & 8 & 28.1 & 10 & 2753 & 33 & 0.012 & -0.03 \\
\hline BMS1341 & 8 & 51.4 & 11 & 2971 & 3 & 0.001 & 0.01 \\
\hline BM711 & 8 & 83.6 & 7 & 2013 & 2 & 0.001 & 0.00 \\
\hline BM757 & 9 & 0.6 & 7 & 2163 & 0 & 0.000 & 0.04 \\
\hline ETH225* & 9 & 8.1 & 7 & 2143 & 1 & 0.000 & 0.01 \\
\hline UWCA9 & 9 & 44.9 & 3 & 478 & 0 & 0.000 & 0.07 \\
\hline BMS1290 & 9 & 59.0 & 11 & 3170 & 3 & 0.001 & 0.01 \\
\hline BMS2295 & 9 & 91.5 & 9 & 1843 & 21 & 0.011 & -0.03 \\
\hline BRN & 10 & 29.2 & 10 & 2221 & 33 & 0.015 & 0.02 \\
\hline BMS1318 & 10 & 73.0 & 9 & 2375 & 1 & 0.000 & 0.02 \\
\hline RM096 & 11 & 31.0 & 8 & 2133 & 0 & 0.000 & 0.02 \\
\hline BM8118 & 11 & 72.4 & 9 & 2816 & 11 & 0.004 & -0.04 \\
\hline HEL13 & 11 & 114.0 & 9 & 1753 & 4 & 0.002 & -0.01 \\
\hline IDVGA57 & 12 & 29.9 & 10 & 2730 & 4 & 0.001 & -0.09 \\
\hline BM860 & 12 & 49.4 & 7 & 1824 & 0 & 0.000 & 0.04 \\
\hline BM4028 & 12 & 79.7 & 7 & 2349 & 0 & 0.000 & 0.03 \\
\hline BMC1222 & 13 & 20.0 & 10 & 2287 & 12 & 0.005 & -0.16 \\
\hline BMS1352 & 13 & 31.0 & 7 & 2147 & 2 & 0.001 & 0.01 \\
\hline
\end{tabular}


Table 1 (Continued). Marker locations, number of sires and cows genotyped, single conflicts per marker, frequency of single conflicts, and deviations from expected heterozygote frequency.

\begin{tabular}{|c|c|c|c|c|c|c|c|}
\hline \multirow[b]{2}{*}{ Marker $^{1}$} & \multirow[b]{2}{*}{$\mathrm{BTA}^{2}$} & \multirow[b]{2}{*}{ Position $^{3}$} & \multicolumn{2}{|c|}{ Number of } & \multicolumn{2}{|c|}{ Single conflicts } & \multirow{2}{*}{$\begin{array}{l}\text { Heterozygosity } \\
\text { obs - ex }\end{array}$} \\
\hline & & & Sires & Cows & Number & Frequency & \\
\hline BMS995 & 13 & 84.1 & 11 & 2899 & 2 & 0.001 & 0.03 \\
\hline ILSTS039 & 14 & $20.0^{5}$ & 7 & 1582 & 0 & 0.000 & 0.02 \\
\hline CSSM66 & 14 & $33.0^{5}$ & 7 & 2066 & 0 & 0.000 & 0.02 \\
\hline BM4305 & 14 & 66.4 & 7 & 1511 & 8 & 0.005 & -0.02 \\
\hline BMS2684 & 15 & 34.9 & 9 & 1226 & 6 & 0.005 & -0.05 \\
\hline HBB & 15 & 39.6 & 7 & 2066 & 0 & 0.000 & 0.03 \\
\hline SPS115* & 15 & 70.0 & 8 & 1978 & 1 & 0.001 & -0.00 \\
\hline TGLA245 & 16 & 6.5 & 5 & 428 & 9 & 0.021 & -0.05 \\
\hline IDVGA68 & 16 & 47.4 & 9 & 2636 & 11 & 0.004 & 0.04 \\
\hline INRA13 & 16 & 88.0 & 3 & 449 & 0 & 0.000 & -0.02 \\
\hline BMS2220 & 17 & 16.0 & 8 & 1313 & 5 & 0.004 & -0.06 \\
\hline IDVGA40 & 17 & 67.0 & 9 & 2662 & 10 & 0.004 & -0.01 \\
\hline BM7109 & 18 & 49.6 & 10 & 2628 & 8 & 0.003 & -0.01 \\
\hline TGLA227* & 18 & 84.7 & 9 & 2205 & 1 & 0.000 & 0.02 \\
\hline BM745 & 19 & 15.9 & 8 & 2271 & 23 & 0.010 & -0.02 \\
\hline BP20 & 19 & 46.5 & 7 & 2113 & 0 & 0.000 & -0.01 \\
\hline IDVGA48 & 19 & 70.7 & 9 & 1928 & 36 & 0.019 & -0.40 \\
\hline BM1225 & 20 & 8.0 & 7 & 2264 & 5 & 0.002 & -0.00 \\
\hline TGLA126* & 20 & 31.2 & 9 & 2376 & 1 & 0.000 & 0.05 \\
\hline BM5004 & 20 & 64.3 & 9 & 1934 & 10 & 0.005 & -0.03 \\
\hline ETH131 & 21 & 32.3 & 6 & 1665 & 2 & 0.001 & -0.02 \\
\hline TGLA122* & 21 & 67.3 & 9 & 2346 & 0 & 0.000 & 0.01 \\
\hline CSSM41 & 22 & 46.3 & 7 & 1984 & 3 & 0.002 & -0.07 \\
\hline CYP21 & 23 & 36.0 & 7 & 2155 & 0 & 0.000 & 0.01 \\
\hline BM7151 & 24 & 6.0 & 9 & 2188 & 28 & 0.013 & 0.02 \\
\hline BMS466 & 24 & 46.0 & 9 & 2477 & 10 & 0.004 & -0.11 \\
\hline ILSTS102 & 25 & 6.5 & 10 & 2890 & 11 & 0.004 & 0.03 \\
\hline BMS1353 & 25 & 45.3 & 9 & 2524 & 8 & 0.003 & -0.00 \\
\hline BMS651 & 26 & 2.5 & 10 & 2758 & 15 & 0.005 & -0.01 \\
\hline BM4505 & 26 & 40.0 & 10 & 2106 & 5 & 0.002 & -0.01 \\
\hline BMS2168 & 27 & 0.0 & 11 & 3101 & 5 & 0.002 & -0.02 \\
\hline BMS641 & 27 & 14.3 & 1 & 562 & 1 & 0.002 & 0.09 \\
\hline BMS689 & 27 & 34.1 & 11 & 3826 & 29 & 0.008 & 0.00 \\
\hline CSSM36 & 27 & 39.8 & 2 & 914 & 10 & 0.011 & 0.01 \\
\hline BM1857 & 27 & 52.7 & 2 & 915 & 10 & 0.011 & 0.00 \\
\hline INRA027 & 27 & 58.4 & 1 & 603 & 2 & 0.003 & 0.04 \\
\hline BM203 & 27 & 64.1 & 1 & 491 & 2 & 0.004 & 0.06 \\
\hline BMC6020 & 28 & 2.0 & 5 & 929 & 7 & 0.008 & -0.15 \\
\hline IDVGA43 & 28 & 27.9 & 9 & 2582 & 47 & 0.018 & -0.24 \\
\hline ARO26 & 29 & 11.0 & 7 & 2037 & 0 & 0.000 & 0.02 \\
\hline BMC6004 & 29 & 57.9 & 10 & 2899 & 1 & 0.000 & -0.00 \\
\hline Means & & & 6.55 & 1815 & 7.01 & 0.004 & -0.004 \\
\hline
\end{tabular}

${ }^{1}$ Markers denoted with an asterisk are included in the International Society for Animal Genetics (ISAG) standard panel for pedigree confirmation.

${ }^{2}$ Bos taurus autosome.

${ }^{3}$ Marker locations are given according to the Clay Center genetic map (http://sol.marc.usda.gov/genome/ cattle/cattle.html), unless otherwise indicated.

${ }^{4}$ Difference between the observed and expected frequencies of heterozygotes, based on the Hardy-Weinberg equilibrium.

${ }^{5}$ Riquet et al. (1999).

ing, "null alleles," or errors in paternity recording. As noted, the Israeli Holstein genome scan included more than 180,000 individual marker genotypes, and a dataset of this magnitude should contain all 4 factors.

Various studies have reported on the presence of null alleles for specific microsatellites (e.g., Petersen and Bendixen, 2000). If one allele fails to amplify, the individual appears to be a homozygote for this marker, even though it is in fact a heterozygote. Progeny of a sire heterozygous for a null allele that receive the null allele will appear to be homozygous for their maternal allele. If the maternal allele is different from the sire's observed allele then no common allele will be observed between the sire and his progeny, and paternity will be erroneously rejected. A sire was declared to be heterozygous for a null allele if the following 3 criteria 
were met: 1) the sire was observed to be apparently homozygous for the microsatellite, 2) there was a preponderance of observed homozygous progeny of the sire as compared with the expected frequency by HardyWeinberg equilibrium as estimated from the observed allelic frequencies; and 3) more than $10 \%$ of the recorded progeny were homozygous for alleles other than the observed putative paternal allele.

The difference between the observed and expected frequency of heterozygotes, based on Hardy-Weinberg equilibrium was computed for each marker, and is also listed in Table 1. The expected frequency of heterozygotes for marker $\mathrm{j}, \mathrm{HEX}_{\mathrm{j}}$, was computed as follows:

$$
\operatorname{HEX}_{\mathrm{j}}=\underset{\substack{\mathrm{K}_{\mathrm{j}} \\ \mathrm{k}_{\mathrm{j}}=1}}{\sum \mathrm{p}_{\mathrm{jk}} \times\left(1-\mathrm{p}_{\mathrm{jk}}\right)}
$$

where $p_{j k}=$ the frequency of allele $k$ of marker $j$, and $\mathrm{K}_{\mathrm{j}}$ is the total number of alleles for marker $\mathrm{j}$. The means frequency of heterozygotes over all markers was 0.68 , and the difference between the observed and expected heterozygosity ranged from -0.40 to 0.15 , with a mean of -0.004 .

Based on these criteria, 3 markers were found with null alleles: CSSM41, IDVGA43, and IDVGA48. One sire was determined to be heterozygous for a null allele for CSSM41, and 3 sires were heterozygous for null alleles for IDVGA43 and IDVGA48. In these cases, a conflict between the genotype of the daughter and the putative sire was declared only if the daughter was observed to be heterozygous for the marker. The difference between the observed and expected heterozygosity for these markers were $-0.07,-0.24$, and -0.40 , respectively. Thus, for these 3 markers, there were fewer heterozygotes than expected by the Hardy-Weinberg equilibrium. Considering all 104 markers, IDVGA43 and IDVGA48 had the highest deviations from the expected frequency of heterozygotes.

If the cow and the putative sire are genotyped for many markers, and paternity recording is incorrect, then it is very unlikely that only a single discrepancy should be observed. These single discrepancies may be due either to mutations or genotyping mistakes. Mutation rates for microsatellites are on the order of $10^{-4}$ (Crawford and Cuthbertson, 1996), whereas genotyping errors are on the order of $1 \%$. When results of 33 laboratories on 40 DNA samples were compared, identical results were not obtained for any of the 9 basic ISAG markers, and 2 laboratories differed in more than one allele (Glowatzki-Mullis and Muntwyler, 2002). Thus, the most likely explanation for single discrepancies for cows genotyped for many markers is that paternity was correctly recorded and the single discrepancy is a geno- typing mistake. Of the 104 markers genotyped, some were more prone to genotyping mistakes. The frequencies of cows with single discrepancies among all cows genotyped for each marker were computed for all 104 markers, and are listed in Table 1. Markers with a frequency of single discrepancies $>1 \%$ were considered to be "problematic" and were deleted from further analysis. Seventeen markers met this criterion, including 2 of the markers with null alleles, leaving 87 markers with 160,470 valid genotypes, and a mean of 1844 genotypes per marker.

\section{Calculation of Exclusion Probabilities}

Exclusion probability for cow i, $\mathrm{Ex}_{\mathrm{i}}$, was calculated as follows (Ron et al., 1996):

$$
\begin{gathered}
\mathrm{J} \\
\mathrm{Ex}_{\mathrm{i}}=1-\underset{\mathrm{j}=1}{\prod}\left[1-\left(1-\mathrm{p}_{\mathrm{ij}}\right)^{* * *} 2\right]
\end{gathered}
$$

where $\mathrm{p}_{\mathrm{ij}}=$ sum of the frequencies of the 2 alleles of cow i for marker j, and $\Pi[y]$ represents the product of [y] from 1 through $J$, where $J$ is the number of markers for which cow $i$ and her putative sire were genotyped. For those markers for which the cow was homozygous, $\mathrm{p}_{\mathrm{ij}}=$ the frequency of the allele of cow $\mathrm{i}$ for marker $\mathrm{j}$. Exclusion probabilities were computed for all cows with less than 2 markers in conflict with the genotype of the putative sire.

Note that if $\mathrm{p}_{\mathrm{ij}}$ are approximately equal for all loci, then $1-\mathrm{Ex}_{\mathrm{i}}$ should be a multiplicative function of the number of markers genotyped. Thus, $\log \left(1-\mathrm{Ex}_{\mathrm{i}}\right)$ should be an approximately linear function of the number of markers. Correlations among $\mathrm{Ex}_{\mathrm{i}}, \log \left(1-\mathrm{Ex}_{\mathrm{i}}\right)$ and the number of markers genotyped per cow were computed. The regression of $\log \left(1-\mathrm{Ex}_{\mathrm{i}}\right)$ on the number of markers genotyped was also computed.

\section{Confirmation of Paternity by Genotypes}

Three categories were determined with respect to paternity confirmation: confirmation, rejection, or undetermined. If no discrepancies were found between the putative daughter and sire genotypes, then paternity recording was declared confirmed if the exclusion probability was $>0.9$. If no discrepancies were found, but the exclusion probability was $<0.9$, then paternity confirmation was declared undetermined. If 2 or more discrepancies were found among the first 20 valid genotypes then paternity was rejected, and generally no further genotyping was performed. If a single discrepancy was found, then genotyping was generally continued. Paternity was declared confirmed if the cow was 
WELLER ET AL.

Table 2. Number of cows by the criteria used for paternity confirmation.

\begin{tabular}{|c|c|c|c|c|c|c|}
\hline \multicolumn{3}{|c|}{ Number of } & \multirow{2}{*}{$\begin{array}{l}\text { Frequency of } \\
\text { discrepancies }\end{array}$} & \multirow{2}{*}{$\begin{array}{l}\text { Exclusion } \\
\text { probability }\end{array}$} & \multicolumn{2}{|c|}{ Paternity } \\
\hline Cows & Genotypes & Discrepancies & & & Status & No. cows \\
\hline $\begin{array}{l}4620 \\
309\end{array}$ & $\begin{array}{l}2-64 \\
20-64\end{array}$ & $\begin{array}{l}0 \\
1\end{array}$ & $\begin{array}{c}0 \\
<0.1\end{array}$ & $\begin{array}{l}>0.9 \\
>0.9\end{array}$ & $\begin{array}{l}\text { Confirmed } \\
\text { Confirmed }\end{array}$ & 4929 \\
\hline $\begin{array}{l}210 \\
133 \\
114\end{array}$ & $\begin{array}{l}1-8 \\
1-19 \\
20-61\end{array}$ & $\begin{array}{l}0 \\
1 \\
2-4\end{array}$ & $\begin{array}{l}0 \\
0.05-1 \\
<0.1\end{array}$ & $\begin{array}{l}\leq 0.9 \\
\ldots \\
\ldots\end{array}$ & $\begin{array}{l}\text { Undetermined } \\
\text { Undetermined } \\
\text { Undetermined }\end{array}$ & 457 \\
\hline $\begin{array}{l}654 \\
\text { Total }\end{array}$ & $3-62$ & $2-11$ & $\geq 0.1$ & $\ldots$ & Rejected & $\begin{array}{r}654 \\
6040\end{array}$ \\
\hline
\end{tabular}

genotyped for at least 20 markers and no further discrepancies were found. In this case, the single discrepancy was assumed to be a mistake or possible mutation. If there were a single discrepancy, but there were $<20$ valid genotypes, then paternity was declared undetermined. If the cow was genotyped for $\geq 20$ markers, paternity was rejected if there were a discrepancy between the cow and putative sire genotypes in at least 3 markers and $\geq 10 \%$ of the microsatellites. Finally, paternity was declared undetermined if discrepancies were found for $\geq 2$ microsatellites, but $<10 \%$ of all the markers genotyped. The number of cows in each category is summarized in Table 2 . There were 457 cows with undetermined paternity. These cows were deleted from all further analyses, leaving 5583 cows; 4929 cows with confirmed paternity and 654 cows with rejected paternity. Preliminary analyses showed that minor changes in the criteria used had very small effects on the number of cows assigned to each paternity status.

\section{Analysis of Factors Affecting Paternity Misidentification}

As noted in the Introduction, the main objective of genotyping was to detect segregating QTL using the daughter design. Therefore, in the early stages of analysis, the genotypes of 96 cows with rejected paternity were not retained. Thus, of the 654 cows with rejected paternity, there were 558 with genotype data on the individual markers. The number of total genotypes, genotypes in conflict with the putative sire, and the frequency of genotypes with conflicts were analyzed. The 96 cows with rejected paternity, but without genotype data, were included in all analyses that did not require specific genotype information.

To determine the possible effect of switching newborn calves on paternity errors, the dates with multiple calvings were determined for each herd. The frequency of misidentified paternity was then computed separately for dates with single and multiple calvings in each herd.
Significance of the difference in the frequency of misidentified paternity was tested by $\chi^{2}$ analysis.

To determine the effect of the inseminator responsible for the mating that resulted in each cow genotyped, the dates of the insemination records of the dam of each cow were compared with the cows' birthdates. Of the 5583 cows with either confirmed or rejected paternity, there were only 39 for which the dam was not recorded. A possible match between an insemination record and the cow's birth record was declared if the insemination date was between 240 and $300 \mathrm{~d}$ prior to partuition. This resulted in some multiple matches, but there were only 17 cows for which a matching insemination record was not found, leaving 5526 cows with at least one possible matching insemination record for their dam. Most of the cases of missing insemination records were apparently due to dams of genotyped cows that changed herds.

For cows with multiple matches, only a single insemination record was retained. First priority was given to insemination records with recorded gestation lengths, even if a negative pregnancy check were recorded (Weller and Ezra, 1997). There were 8 cases in which both gestation length and a negative pregnancy check were recorded. The negative pregnancy check was assumed to be a mistake for these records. If no gestation length were recorded in the herdbook, then priority was given to records with positive pregnancy checks. If gestation length was not recorded, and there were multiple records with positive pregnancy checks, or none of the records had positive pregnancy checks, then the insemination resulting in the longest pregnancy interval up to $300 \mathrm{~d}$ was retained. There remained a single cow for which gestation length was not recorded and the pregnancy check was negative on the only matching insemination record. The service sire and sire of the genotyped cows were the same and paternity was confirmed based on the genetic markers. We therefore assumed that for this cow the negative pregnancy check was a mistake. After these edits, there were 2 cows 
for which the service sire on the insemination record differed from the recorded sire of the genotyped cow. Paternity was confirmed for both cows, but neither gestation length nor a pregnancy check was recorded. These records were also retained. The putative gestation length was computed for each cow with a matching insemination record. The relationship between the recorded gestation period and the frequency of rejected paternity was determined by a $\chi^{2}$ test. Gestation period was divided into 6 categories of equal length.

The geographical region for each herd was determined and matched to the cow record. Seven geographical regions based chiefly on climate are defined in the Israeli Holstein herdbook. There were at least 318 cows from all the geographical regions, except for the Arava Valley. There was only one cow from a herd located in this region.

The effects of putative sire, birth year, herd, region, and inseminator on the frequency of rejected paternity were tested by the following linear model, termed model I:

$$
P_{i j k l m n}=S_{i}+B_{j}+R_{k}+H_{k l}+T_{m}+e_{i j k l m n}
$$

where $P_{i j k l m n}$ is the paternity confirmation score $(0$ for rejected paternity and 1 for confirmed paternity) of cow $n$, putative daughter of sire $i$, born in birth year $j$, from herd $\mathrm{l}$ of region $\mathrm{k}$, produced by insemination technician $\mathrm{m} ; \mathrm{S}_{\mathrm{i}}$ is the effect of sire $\mathrm{i} ; \mathrm{B}_{\mathrm{j}}$ is the effect of birth year $j ; R_{k}$ is the effect of geographical region $k ; H_{k l}$ is the effect of herd l within region $\mathrm{k} ; \mathrm{T}_{\mathrm{m}}$ is the effect of insemination technician $\mathrm{m}$; and $\mathrm{e}_{\mathrm{ijk} \mathrm{klm}}$ is the random residual. Birth years, herds, regions, and inseminators with less than 10 records were deleted, leaving 5320 cows. Records from 1 region, 2 birth years, 7 inseminators, and 68 herds were deleted. Herds were nested within region; all other effects were factorial.

In model II, the class effect of birth year was replaced by the regression effect of birth date. Least square means were not estimable by model I or II because of confounding between herds and inseminators. In general, each inseminator worked an area consisting of several herds. Least square means were computed from 2 additional models based on model I. In model III, the herd effect was deleted, and in model IV, the inseminator effect was deleted. Model V included only the effects that were significant in model I $(P<0.05)$. These models were compared based on coefficients of determination and $F$-values derived from the "type-III" sums of squares (SAS Inst., Inc., Cary, NC). Finally, in model VI, paternity confirmation score was analyzed by PROC CATMOD (SAS) using maximum likelihood estimation with generalized logits as the response function. Model VI included the effects of region, sire, and birth year.

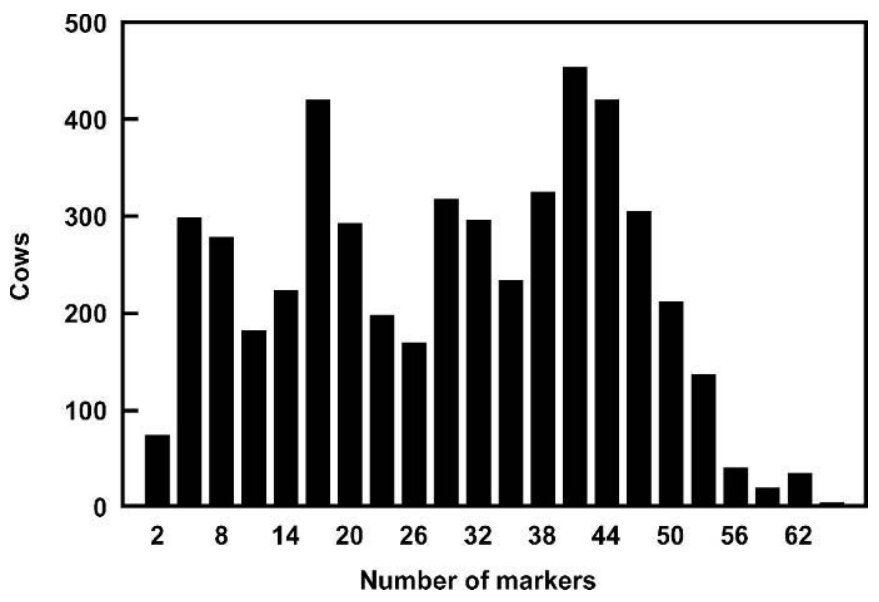

Figure 1. Number of cows with confirmed paternity by number of markers genotyped.

Significance could not be obtained for models that included either the inseminator or herd effect because of the large number of empty cells.

\section{RESULTS}

The total frequency of rejected paternity determinations was $11.7 \%$. The number of cows with confirmed paternity by number of markers genotyped is given in Figure 1. The number of markers for cows with confirmed paternity ranged from 2 to 64 with a mean of 29.4. $\log _{10}\left(1-\mathrm{Ex}_{\mathrm{i}}\right)$ for cows with exclusion probabilities $>0.9$ ranged from -1 to -26.6 . The correlation between $\log _{10}\left(1-\mathrm{Ex}_{\mathrm{i}}\right)$ and number of markers per cow was -0.96 . The regression of number of markers on $\log _{10}\left(1-\mathrm{Ex}_{\mathrm{i}}\right)$ was -0.361 , with a standard error of 0.002 . The y-intercept was -0.088 , with a standard error of 0.050 . Thus, on the average, 2.5 markers are required to obtain an exclusion probability of 0.9 , and 5.3 markers are required to obtain an exclusion probability of 0.99 . The number of markers for cows with exclusion probabilities $<0.9$ ranged from 1 to 8 with a mean of 3.2. This value is slightly greater than the value of 2.5 predicted by the regression equation.

The number of cows with rejected paternity for the number of markers genotyped and the number of markers in conflict with their sire's genotype are given in Figure 2. There were 7 cows with rejected paternity and $>40$ markers that were not included in the figure. The number of markers genotyped per cow for the cows with rejected paternity ranged from 3 to 62 , with a mean of 16.8. The number of markers in conflict ranged from 2 to 16, with a mean of 4.5. As noted, genotyping of cows with rejected paternity was generally discontinued once at least 2 markers in conflict with the sire 


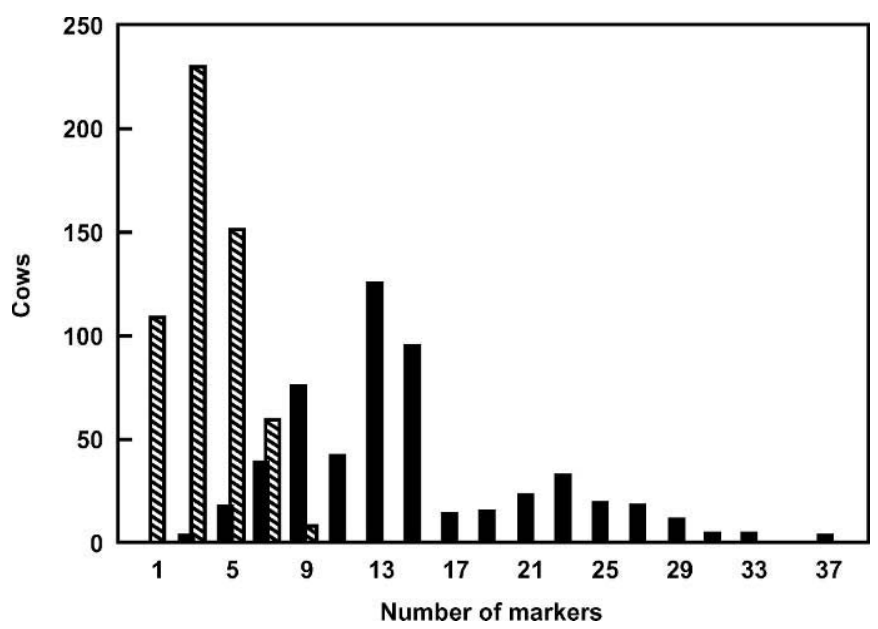

Figure 2. Number of cows with rejected paternity by number of markers genotyped (solid bars), and number of markers in conflict with their sire's genotype (hatched bars). An additional 7 cows genotyped for $>40$ markers are not shown.

genotype were found. However, the markers were run in panels of up to 15 markers, and all markers in the panel were analyzed jointly. The number of cows with rejected paternity by the fraction of markers in conflict with the sire is given in Figure 3. The fraction ranged from 0.1 to 1.0 , with a mean of 0.30 . As noted in the methods, a frequency of at least 0.1 marker discrepancies was required to reject paternity.

The number of levels, records, $F$-values, and coefficients of determination $\left(\mathrm{R}^{2}\right)$ in the linear model analyses are given in Table 3. For the categorical model analysis, $\chi^{2}$ values were computed instead of $F$-values, and

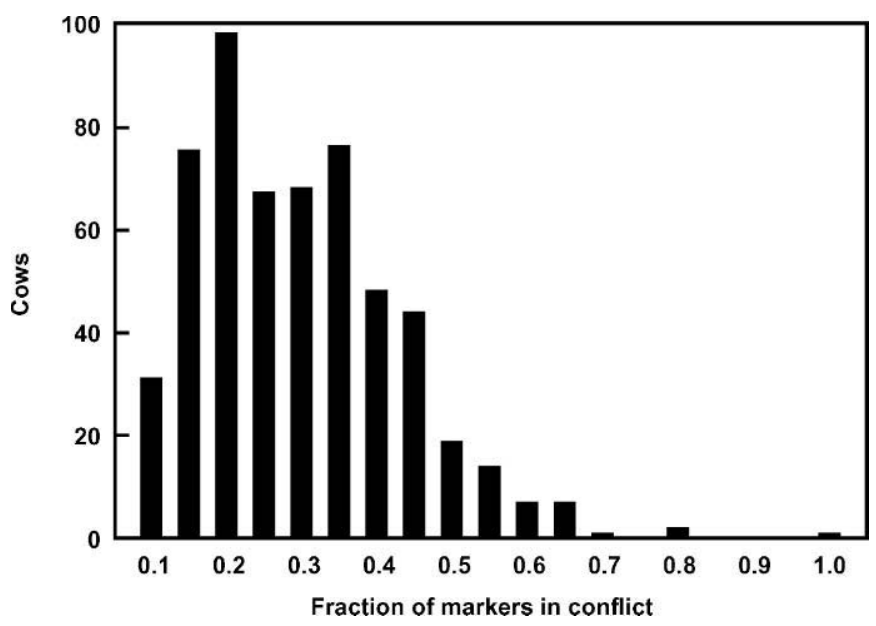

Figure 3. Number of cows with rejected paternity by the fraction of markers in conflict with the sire.
$\mathrm{R}^{2}$ was not computed. The $\mathrm{R}^{2}$ at 0.132 was highest for model I. Although the effects of region and herd were not significant in model I, both effects were highly significant in model IV, which did not include the inseminator effect. As noted previously, the herd and inseminator effects are highly confounded because most inseminators worked a specific region consisting of several herds. The effect of region was also not significant in model III, which included the inseminator effect, but not the herd effect. The effects of sire and birth year were also strongly confounded. Some sires were used chiefly in the early years, whereas other sires were used in the later years. The sire effect was highly significant in all models, whereas the class effect of birth year was only marginally significant in the linear models. The linear effect of birth date was not significant in model II, but the class effect of birth year was significant $(P=0.0025)$ in the categorical model that also included the sire effect. The $\mathrm{R}^{2}$ for model $\mathrm{V}$, which included only the effects significant in model I, was 0.110 , as compared with 0.132 for the complete model. The 3 effects included in the categorical model analysis were all significant at $P<0.005$.

The number of cows genotyped, the number of cows with rejected paternity, the frequency of rejected paternity, and the model III least square means by recorded sire are given in Table 4 . Frequency of paternity rejection was lowest for sire 3241 (7\%), and 3 times higher (22\%) for sire 3099. The high frequency of mistakes for sire 3099, double the overall average, is surprising, and may be due to a mistake in semen labeling at the AI institute. This sire was used chiefly in the earlier years included in the analysis, whereas 3241 was used chiefly in the later years. Least square means were generally lower than the simple means for the sires with lower numbers that were used earlier, and higher than the simple means for the sires that were used later. Standard errors of the least square means ranged from 0.017 to 0.026 .

The number of cows genotyped, the number of cows with rejected paternity, the frequency of rejected paternity, and the model III least square means by birth year are given in Table 5. The frequency of rejected paternity ranged from $19 \%$ in 1990 to $6 \%$ in 1997 . Although a clear trend of reduction in the rate of rejected paternity is evident in the simple means, this is not the case for the least square means. Although the lowest least square mean was for 1997, the last birth year included in the analysis, the highest least square mean, was for 1994, in the middle of the distribution. Standard errors ranged from 0.013 to 0.045 . As noted previously, the linear effect of birth date was not significant.

The number of cows genotyped, the number of cows with rejected paternity, the frequency of rejected pater- 
Table 3. The number of levels, records, $F$-values, and coefficients of determination $\left(\mathrm{R}^{2}\right)$ in the linear model analyses (5320 cows).

\begin{tabular}{|c|c|c|c|c|c|c|}
\hline Model & Model type & Factor & Levels & $F$-values $^{1}$ & Significance & $\mathrm{R}^{2}$ \\
\hline \multirow[t]{5}{*}{ I } & \multirow[t]{5}{*}{ Linear } & Inseminator & 50 & 4.38 & $<0.0001$ & \multirow[t]{5}{*}{0.132} \\
\hline & & Region & 6 & 0.59 & $\mathrm{NS}^{2}$ & \\
\hline & & Herd & 123 & 1.08 & NS & \\
\hline & & Sire & 11 & 3.34 & 0.0002 & \\
\hline & & Birth year & 8 & 2.05 & 0.0451 & \\
\hline \multirow[t]{5}{*}{ II } & \multirow[t]{5}{*}{ Linear } & Inseminator & 50 & 4.38 & $<0.0001$ & \multirow[t]{5}{*}{0.130} \\
\hline & & Region & 6 & 0.49 & NS & \\
\hline & & Herd & 123 & 1.10 & NS & \\
\hline & & Sire & 11 & 3.11 & 0.0006 & \\
\hline & & Birth date ${ }^{3}$ & & 0.86 & NS & \\
\hline \multirow[t]{4}{*}{ III } & \multirow[t]{4}{*}{ Linear } & Inseminator & 50 & 10.24 & $<0.0001$ & \multirow[t]{4}{*}{0.111} \\
\hline & & Region & 6 & 0.94 & NS & \\
\hline & & Sire & 11 & 3.64 & $<0.0001$ & \\
\hline & & Birth year & 8 & 2.49 & 0.0150 & \\
\hline \multirow[t]{4}{*}{ IV } & \multirow[t]{4}{*}{ Linear } & Region & 6 & 10.90 & $<0.0001$ & \multirow[t]{4}{*}{0.097} \\
\hline & & Herd & 123 & 3.46 & $<0.0001$ & \\
\hline & & Sire & 11 & 3.21 & 0.0004 & \\
\hline & & Birth year & 8 & 2.19 & 0.0325 & \\
\hline \multirow[t]{3}{*}{ V } & \multirow[t]{3}{*}{ Linear } & Inseminator & 50 & 11.79 & $<0.0001$ & \multirow[t]{6}{*}{0.110} \\
\hline & & Sire & 11 & 3.70 & $<0.0001$ & \\
\hline & & Birth year & 8 & 2.42 & 0.0179 & \\
\hline \multirow[t]{3}{*}{ VI } & \multirow[t]{3}{*}{$\operatorname{Logistic}^{4}$} & Region & 6 & 68 & $<0.0001$ & \\
\hline & & Sire & 11 & 36 & $<0.0001$ & \\
\hline & & Birth year & 8 & 22 & 0.0025 & \\
\hline
\end{tabular}

\footnotetext{
${ }^{1}$ For type III sums of squares.

${ }^{2}$ Not significant.

${ }^{3}$ Number of categories is not listed because birth date was a linear regression effect.

${ }^{4}$ The $\chi^{2}$ values for the maximum likelihood estimates are given instead of $F$-values. The $\mathrm{R}^{2}$ values are not computed for the logistic analysis.
}

nity, and the model III least square means by geographical region are given in Table 6. The frequency of rejected paternity was lowest in the Jordan Valley region $(5 \%)$ and highest in "other areas" (15\%). Similar to both sire and birth year, the frequency of incorrect paternity in the worst level was 3 times higher than in the best level. Differences among the least square means were smaller than the difference among the simple means.

Table 4. The number of cows genotyped, the number of cows with rejected paternity, and the frequency of rejected paternity by recorded sire.

\begin{tabular}{|c|c|c|c|c|}
\hline \multirow[b]{2}{*}{ Sire } & \multicolumn{2}{|c|}{ Number of cows } & \multirow{2}{*}{$\begin{array}{l}\text { Frequency } \\
\text { of rejected } \\
\text { paternity }\end{array}$} & \multirow{2}{*}{$\begin{array}{l}\text { Least } \\
\text { square } \\
\text { means }^{1}\end{array}$} \\
\hline & Genotyped & $\begin{array}{l}\text { Rejected } \\
\text { paternity }\end{array}$ & & \\
\hline 2278 & 748 & 94 & 0.126 & 0.104 \\
\hline 2283 & 414 & 53 & 0.128 & 0.120 \\
\hline 2357 & 563 & 59 & 0.105 & 0.062 \\
\hline 3070 & 729 & 94 & 0.129 & 0.099 \\
\hline 3089 & 542 & 53 & 0.098 & 0.080 \\
\hline 3099 & 275 & 61 & 0.222 & 0.180 \\
\hline 3208 & 530 & 40 & 0.075 & 0.084 \\
\hline 3212 & 532 & 74 & 0.126 & 0.118 \\
\hline 3241 & 572 & 40 & 0.070 & 0.087 \\
\hline 3258 & 346 & 40 & 0.116 & 0.153 \\
\hline 3274 & 332 & 46 & 0.139 & 0.150 \\
\hline Total & 5583 & 654 & 0.117 & \\
\hline
\end{tabular}

${ }^{1}$ By Model III, 5320 cows were included in the analysis.
The number of cows genotyped, the number of cows with rejected paternity, the frequency of rejected paternity, and the model IV least square means of 5 herds with the highest proportion of rejected paternity, and the 5 herds with the lowest proportions of rejected paternity and a minimum size of 50 cows are given in Table 7 . The proportion of rejected paternity ranged from 32 to $74 \%$ for the 5 herds with the highest proportion of rejected paternity. These 5 herds included $<4 \%$

Table 5. The number of cows genotyped, the number of cows with rejected paternity, and the frequency of rejected paternity by birth year.

\begin{tabular}{|c|c|c|c|c|}
\hline \multirow[b]{2}{*}{ Birth year } & \multicolumn{2}{|c|}{ Number of cows } & \multirow{2}{*}{$\begin{array}{l}\text { Frequency } \\
\text { of rejected } \\
\text { paternity }\end{array}$} & \multirow{2}{*}{$\begin{array}{l}\text { Least } \\
\text { square } \\
\text { means }^{1}\end{array}$} \\
\hline & Genotyped & $\begin{array}{l}\text { Rejected } \\
\text { paternity }\end{array}$ & & \\
\hline 1990 & 57 & 11 & 0.193 & 0.143 \\
\hline 1991 & 407 & 60 & 0.147 & 0.129 \\
\hline 1992 & 1036 & 121 & 0.117 & 0.131 \\
\hline 1993 & 903 & 109 & 0.121 & 0.116 \\
\hline 1994 & 1313 & 174 & 0.133 & 0.153 \\
\hline 1995 & 1000 & 90 & 0.090 & 0.129 \\
\hline 1996 & 766 & 83 & 0.108 & 0.088 \\
\hline 1997 & 99 & 6 & 0.061 & 0.009 \\
\hline Total $^{2}$ & 5581 & 654 & 0.117 & \\
\hline
\end{tabular}

${ }^{1}$ By Model III, 5320 cows were included in the analysis.

${ }^{2}$ Two cows were born outside the range of 1990 to 1997. 
Table 6. The number of cows genotyped, the number of cows with rejected paternity, and the frequency of rejected paternity by geographical region.

\begin{tabular}{lccll}
\hline & \multicolumn{2}{c}{ Number of cows } & & Least \\
\cline { 2 - 3 } Region & Genotyped & $\begin{array}{l}\text { Rejected } \\
\text { paternity }\end{array}$ & $\begin{array}{l}\text { Frequency } \\
\text { of means }\end{array}$ & $\begin{array}{l}\text { square } \\
\text { means }\end{array}$ \\
\hline Mountains & 123 & 15 & 0.122 & 0.110 \\
Jordan Valley & 996 & 51 & 0.051 & 0.084 \\
Jezrael Valley & 318 & 29 & 0.091 & 0.107 \\
Negev & 955 & 139 & 0.146 & 0.119 \\
Other regions & 1063 & 160 & 0.151 & 0.139 \\
Coastal plain & 2127 & 260 & 0.122 & 0.117 \\
Total $^{2}$ & 5582 & 654 & 0.117 & 0.110 \\
\hline
\end{tabular}

${ }^{1}$ By Model III, 5320 cows were included in the analysis.

${ }^{2}$ One additional cow was from the Arava region.

of all the cows genotyped, but included $14 \%$ of the cows with rejected paternity. The proportion of rejected paternity ranged from 0 to $3.5 \%$ for the 5 herds with the lowest proportion of rejected paternity and minimum size of 50 recorded cows. The least square means were very similar to the simple means for the herds included in Table 7. There were 13 herds with at least 10 genotyped cows and no cases of rejected paternity. Ten herds had least square means $<0$, considering all herds included in the linear model analyses, but all of these herds had relatively few records.

Of the 5583 cows with paternity either confirmed or rejected, $3404(61 \%)$ were born on dates with multiple calvings in the herd, and 2179 (39\%) were born on dates with a single calving. The rate of paternity errors were $10.8 \%$ for dates with single births, and $12.3 \%$ for dates with multiple births. Although this difference of $1.5 \%$ is in the expected direction, the $\chi^{2}$ probability was 0.10 . This supports the conclusion from model I that the herd effect is not a significant factor in determining the rate of paternity misidentification.

Mean computed gestation length was $275.7 \mathrm{~d}$, with a standard deviation of $5.1 \mathrm{~d}$. The number of cows genotyped, the number of cows with rejected paternity, and the frequency of rejected paternity by gestation length category are given in Table 8. Frequency of rejection was lowest for the "normal" gestation lengths, 270 to $289 \mathrm{~d}$, and higher for the cows of either short or long gestations. The relationship between recorded gestation period and frequency of rejected paternity was tested by $\chi^{2}$ with the 6 categories as listed in Table 8 , and with the first 2 categories combined to obtain the minimum required expected cell values. In both cases the $\chi^{2}$ values were significant at $P<0.005$. Thus, if the computed gestation length is deviant, the probability of incorrect paternity is increased.

Of the cows with rejected paternity and identified inseminator, there were 131 cows for which a match
Table 7. The number of cows genotyped, the number of cows with rejected paternity, and the frequency of rejected paternity for the 5 herds with the highest fraction of rejected paternity, and the 5 herds with the lowest fractions of rejected paternity and at least 50 cows.

\begin{tabular}{lrrlll}
\hline & \multicolumn{2}{c}{ Number of cows } & & Requency \\
\cline { 2 - 4 } Herd $^{1}$ & Genotyped & $\begin{array}{l}\text { Rejected } \\
\text { paternity }\end{array}$ & $\begin{array}{l}\text { Frequst } \\
\text { of means }\end{array}$ & $\begin{array}{l}\text { square } \\
\text { means }\end{array}$ \\
\hline 435000 & 38 & 28 & 0.736 & 0.789 \\
707000 & 13 & 6 & 0.462 & 0.473 \\
274000 & 78 & 29 & 0.372 & 0.333 \\
370000 & 61 & 20 & 0.328 & 0.319 \\
424000 & 19 & 6 & 0.316 & 0.287 \\
334000 & 115 & 4 & 0.035 & 0.048 \\
262000 & 58 & 2 & 0.034 & 0.034 \\
176000 & 59 & 2 & 0.034 & 0.019 \\
590000 & 78 & 2 & 0.026 & 0.019 \\
188000 & 56 & 0 & 0.000 & 0.015 \\
\hline
\end{tabular}

${ }^{1}$ By Model IV.

was found to 2 or more insemination records and with at least 2 different service sires listed. Thus incorrect determination of the sire due to multiple inseminations of the dam with semen from different sires can explain at most $20 \%$ of the incidents of rejected paternity.

The number of cows genotyped, the number of cows with rejected paternity, and the frequency of rejected paternity and the model III least square means of the 5 inseminators with the highest proportion of rejected paternity, and the 5 inseminators with the lowest proportions of rejected paternity serving at least 50 cows are given in Table 9 . The proportion of rejected paternity ranged from 27 to $82 \%$ for the 5 inseminators with the highest proportion of rejected paternity. These 5 inseminators were responsible for $12 \%$ of all the cows with identified inseminator, but for $33 \%$ of the 646 cows with identified inseminator and rejected paternity. There was one additional inseminator with a rejection frequency of $>20 \%$. Deleting the cows produced by these 6 inseminators, the overall proportion of cows with rejected paternity and identified inseminator was reduced to $8.3 \%$. Inseminator 202 , with $82 \%$ rejected paternity

Table 8. The number of cows genotyped, the number of cows with rejected paternity, and the frequency of rejected paternity by computed gestation length.

\begin{tabular}{lccl}
\hline & \multicolumn{2}{c}{ Number of cows } & \\
\cline { 2 - 3 } $\begin{array}{l}\text { Gestation } \\
\text { length (d) }\end{array}$ & Genotyped & $\begin{array}{l}\text { Rejected } \\
\text { paternity }\end{array}$ & $\begin{array}{l}\text { Frequency } \\
\text { of rejected } \\
\text { paternity }\end{array}$ \\
\hline $240-249$ & 6 & 1 & 0.167 \\
$250-259$ & 13 & 3 & 0.231 \\
$260-269$ & 350 & 51 & 0.146 \\
$270-279$ & 3594 & 398 & 0.111 \\
$280-289$ & 1532 & 183 & 0.119 \\
$290-300$ & 32 & 10 & 0.312 \\
Total & 5527 & 646 & 0.117 \\
\hline
\end{tabular}


Table 9. The number of cows genotyped, the number of cows with rejected paternity, and the frequency of rejected paternity for the 5 inseminators with the highest fraction of rejected paternity, and the 5 inseminators with the lowest fractions of rejected paternity and responsible for at least 50 cows.

\begin{tabular}{lccll}
\hline & \multicolumn{2}{c}{ Number of cows } & & Least \\
\cline { 2 - 3 } Inseminator & Genotyped & $\begin{array}{l}\text { Rejected } \\
\text { paternity }\end{array}$ & $\begin{array}{l}\text { Frequency } \\
\text { of means }\end{array}$ & $\begin{array}{l}\text { square } \\
\text { means }\end{array}$ \\
\hline 202 & 57 & 47 & 0.825 & 0.800 \\
125 & 36 & 11 & 0.306 & 0.305 \\
225 & 177 & 53 & 0.300 & 0.265 \\
209 & 342 & 94 & 0.275 & 0.256 \\
142 & 52 & 14 & 0.269 & 0.255 \\
113 & 266 & 12 & 0.045 & 0.069 \\
137 & 145 & 6 & 0.041 & 0.065 \\
146 & 199 & 7 & 0.035 & 0.050 \\
116 & 78 & 2 & 0.026 & 0.030 \\
143 & 80 & 2 & 0.025 & 0.015 \\
\hline
\end{tabular}

${ }^{1}$ By Model III.

worked in 3 of the 5 herds with the highest frequency of rejected paternity, including herd 435000 . The proportion of rejected paternity ranged from 2.5 to $4.5 \%$ for the 5 inseminators with the lowest proportion of rejected paternity and at least 50 recorded cows. The least square means were very similar to the simple means, indicating the dominance of this effect in the model III analysis. Standard errors ranged from 0.025 to 0.050 . There were 2 inseminators with no cases of rejected paternity, but these inseminators were listed for only 10 and 15 cows.

\section{DISCUSSION}

Nearly all previous studies that have estimated the frequency of incorrect paternity determination have used up to 11 markers. In the current study, which was a by-product of a genome scan for QTL, 104 markers were considered. Of these, 17 were rejected because of high genotyping error rates. This is not surprising considering that in this study, markers were selected based on genomic location and polymorphism. Ease and reliability of genotyping were only secondary considerations. The $11.7 \%$ frequency of rejected paternity determinations in this study is in agreement with most previous studies on this and other populations. Ron et al. (1996) obtained a paternity rejection rate of $5.2 \%$ in this same population, based on genotyping 12 microsatellite markers with radioactive labeling on 173 cows and their 4 putative sires, but most of the cows had valid genotypes for only a fraction of the markers. Mean exclusion probability was 0.85 ; thus, the predicted sire misidentification rate was $6.1 \%$. More recently, Ron et al. (2003) found a paternity misidentification rate of $6.25 \%$ for this population based on 244 elite cows. However, they required 2 markers in conflict, and cows were genotyped for, at most, 9 markers. Single discrepancies were considered genotyping mistakes. Thus, this rate is probably an underestimate of the true value. Visscher et al. (2002) found an overall paternity error rate of $10 \%$ in the UK dairy population based on analysis of 568 cows for 11 unlinked microsatellites. Using blood groups and protein polymorphisms, Beechinor and Kelly (1987) found a paternity rate of 8 to $20 \%$ in Ireland, Christensen et al. (1982) reported rates between 5 and $15 \%$ in Danish dairy cattle, and Geldermann et al. (1986) found a misidentification rate of $13 \%$ in German dairy cattle. Finally, Bovenhuis and van Arendonk (1991) extrapolated an error rate of $12 \%$ in the Netherlands based on milk protein genotypes.

Of the 7 causes listed by Christensen et al. (1982) for paternity mistakes, the main factors appear to be 2 and 4: "AI technicians incorrectly identifying semen samples" and "errors when the bull's herdbook number or name is entered into the insemination record." As noted previously, factors 5 and 6 are not applicable under the Israeli Holstein recording system. The analysis of the insemination records indicate that factor 3 , "insemination of cows already pregnant by a previous insemination," can explain at most $20 \%$ of the cases of rejected paternity. Factor 7, "interchange of calves at the farm," does not seem to be a major factor, as demonstrated by the small difference in paternity error rates between cows born on dates with multiple births as compared with cows born on dates with single births in the herd. Furthermore, the herd effect was not significant in analysis models that also included the inseminator effect.

It is more difficult to quantify the effect of the first factor: "mistakes by AI institutes in labeling semen." The effect of putative sire was significant in all models tested, and this seems to be due mostly to the contribution of sire 3099 with a rejection frequency of $22 \%$ and a least squares mean of 0.18 . The most likely explanation would be a mistake in labeling a semen ejaculation from this sire at the AI institute, although there is no way to confirm this at present. Each ejaculation produces about 400 semen doses, which should result in approximately 40 milking cows. Paternity was rejected for 61 cows listed as daughters of sire 3099. This is about 30 cows more than expected, as compared with the population mean. Thus, the additional 30 cows with rejected paternity can easily be explained by erroneously attributing a single ejaculation from some other sire to 3099. It should be noted that since relatively few daughters of this sire were still alive when collection of semen began, special efforts were made to obtain every available cow recorded as progeny of this sire. 
The adoption of hand-held terminals for data entry by the inseminators in Israel in the south of the country and development of a bar code system for each cow during 1993 to 1994 should have resulted in a significant reduction in paternity recording errors. Nevertheless, the linear regression of birth date in model II at $-0.005 \% / y r$ was not significant. The highest year least square mean was for 1994, in the middle of the time period analyzed.

It is necessary to add an eighth factor to the seven causes for paternity rejection listed by Christensen et al. (1982): mistakes in the paternity confirmation laboratory that result in rejection of paternity of cows with correct paternity identification. Incorrect rejection of paternity by the laboratory could be caused either by genotyping mistakes, null alleles, mutation, or sample switching. As noted, the frequency of mutation for microsatellites is very low and should not be a significant factor relative to the other causes of error. Genotyping mistakes can make a major contribution to paternity rejection, especially for markers that are difficult to genotype.

Null alleles mimic genotyping errors and the extent of the null allele phenomenon may vary with different annealing temperatures used for PCR (Petersen and Bendixen, 2000). Averaged over all markers, the mean difference between observed and expected frequency of heterozygotes was virtually zero. However, there were 11 markers with an absolute difference $>0.1$. Even with 300 genotypes, a difference of this magnitude is highly significant by a binomial test. Of these, 4 were markers with $>1 \%$ single discrepancies, including 2 of the markers with null alleles. The reason for the large difference between observed and expected heterozygote frequency for the remaining 7 markers is not clear. Five of these markers had lower than expected frequency of heterozygotes, and may therefore also be due to null alleles, even though sires with null alleles were not detected. Furthermore, Hardy-Weinberg equilibrium assumes random mating, which clearly is not the case for this population.

We required at least 2 markers in conflict between the sire and daughter and at least $10 \%$ of the markers with valid genotypes. Assuming a $1 \%$ rate of discrepancy between the genotypes of the sire and progeny due to incorrect genotyping and mutation, the probability of erroneously rejecting paternity based on the binomial distribution would be 0.005 if 11 markers are genotyped, and at least 2 markers in conflict are required for rejection of paternity.

The effect of sample switching is more difficult to evaluate. The extremely poor results obtained in herd 435000 were originally considered suspect. Therefore, a sample of cows for this herd was independently resam- pled, and genotypes were determined on the new sample. The results were nearly identical to the original sample.

Bredbacka and Koskinen (1999) found a mean exclusion probability of $99.91 \%$ in Holstein-Friesians using the 9 basic markers of the ISAG panel. This corresponds well with the value of $99.95 \%$ for 9 markers obtained by the regression of $\log _{10}\left(1-\mathrm{Ex}_{\mathrm{i}}\right)$ on the number of markers. Although the regression results indicate that an exclusion probability of $>90 \%$ is obtained on the average with 3 microsatellites and $>99 \%$ with 6 microsatellites, in practice, more markers will be required for definitive parental confirmation. If 2 markers in conflict are required to verify exclusion and exclusion probabilities are assumed equal for all markers, then based on the binomial distribution, the probability of exclusion will be: $1-\left[p^{J}+J(1-p) p^{J-1}\right]$, where $p$ is the nonexclusion probability, and $J$ is the number of markers. Based on the regression of the $\log _{10}\left(1-\mathrm{Ex}_{\mathrm{i}}\right)$ on the number of markers, the mean nonexclusion probability per marker was 0.436 . Using this value, at least 6 markers are required to obtain an exclusion probability of $90 \%$, and 9 markers are required to obtain an exclusion probability of $99 \%$. Since not all genotypes will be readable, 11 microsatellites can be considered a reasonable minimum for paternity verification, and this is the number included in the current ISAG panel. Two markers, INRA23 and TGLA53, were added to the original 9 (Bredbacka and Koskinen, 1999). Neither of these was genotyped in the current study. Although on average 26.6 markers per cow were genotyped in the current study, there were still 457 cows (7.5\%) for which paternity was considered "undetermined." It should be noted though, that the criteria used for paternity determination were much stricter than for all previous studies.

The formula used to determine exclusion probabilities assumed that the markers were independently distributed, and that the actual and putative sires were unrelated. However, as can be seen in Table 1, many of the markers analyzed were genetically linked, and many widely used sires were related. The first factor should not significantly affect the exclusion probability if the true and recorded sires are not closely related. In this case, linkage phase relationships will not be maintained, unless the markers are very tightly linked. The fact that the true and recorded sire may be related will affect exclusion probabilities. For example, if the putative and true sires were half-sibs, then there is at least a $50 \%$ chance that the 2 sires will have at least one allele identical by descent for any particular marker.

Various studies have estimated the effect of pedigree mistakes on the rate of genetic gain. Geldermann et al. (1986) concluded that the loss in response should be similar to the proportion of progeny misidentified. More 
recent studies have found smaller losses. Israel and Weller (2000) conducted a stochastic simulation study of a large dairy cattle population undergoing selection to investigate the effect of a $10 \%$ incorrect paternity on genetic progress over a 20 -yr period. They estimated that the annual rate of response was reduced by 3 to $4 \%$. Visscher et al. (2002) predicted a loss in response of $2 \%$ for one round of sire selection using the same heritability (0.25) and progeny group size (100), as a result of reduced reliability. This difference between these 2 studies may reflect both the impact of incorrect identification of both sexes (e.g., daughters of dams with incorrect pedigrees occurred in the simulation of Israel and Weller (2000)) and the accumulated effect of pedigree errors over multiple generations. Banos et al. (2001) found that a postulated paternity error rate of $11 \%$ for sires used in international genetic evaluations decreased genetic trends by 11 to $15 \%$.

By genotyping approximately 1000 cows per year, it should be possible to identify problematic insemination technicians. This should reduce the rate of paternity error from approximately 12 to $8 \%$ and result in at least a $1 \%$ increase in the rate of genetic gain. Using vaginal swabs (Ron et al., 2003), the cost of obtaining DNA samples is negligible compared with genotyping cost of approximately US $\$ 25$ per individual (J. McSweeny, H. Winkeler, and C. Weimann, personal communication). Thus, the total costs for genotyping 1000 cows/yr will be about $\$ 25,000$. If the annual rate of genetic gain is $100 \mathrm{~kg}$ of economically corrected milk per year, then an additional $1 \%$ genetic gain will be $1 \mathrm{~kg} / \mathrm{yr}$. Assuming a profit value of $\$ 0.1 / \mathrm{kg}$ and a population of 100,000 , this translates into a nominal annual gain of $\$ 10,000 /$ yr. However, genetic gains are cumulative and eternal. Weller (1994) showed that with a discount rate of $8 \%$, a lag of $5 \mathrm{yr}$ prior to first gain, and a profit horizon of $20 \mathrm{yr}$, the break-even point between costs and returns will be reached within $20 \mathrm{yr}$ if nominal annual gains are at least 0.31 of the nominal annual costs. Thus, the proposed "quality-control" program is economically justified. In addition, the DNA samples collected could be used for additional studies.

\section{CONCLUSIONS}

The overall frequency of rejected paternity was $11.7 \%$. The main causes of incorrect paternity recording appear to be inseminator recording mistakes, and possibly mistakes with respect to semen labeling at the AI institutes. Incorrect paternity recording due to multiple inseminations by different sires could explain at most $20 \%$ of the paternity mistakes. Switching between calves born on the same day is not a major factor in paternity errors. Instituting a system of quality control, especially at the level of the inseminator, should reduce paternity errors to no more than $8 \%$, and increase genetic progress by at least $1 \%$.

\section{ACKNOWLEDGMENTS}

This research was supported by a grant from the Israel Milk Marketing Board and the US-Israel Binational Agricultural Research and Development fund (BARD). We thank all the herd managers in Israel who allowed us to collect blood from their cows and the Sion AI institute for providing semen of the sires.

\section{REFERENCES}

Banos, G., G. R. Wiggans, and R. L. Powell. 2001. Impact of paternity errors in cow identification on genetic evaluations and international comparisons. J. Dairy Sci. 84:2523-2529.

Beechinor, J. G., and E. P. Kelly. 1987. Errors of identification amongst cattle presented as progeny of some bulls used in the artificial insemination service in Ireland. Ir. Vet. J. 41:348-353.

Bovenhuis, H., and J. A. M. van Arendonk. 1991. Estimation of milk protein gene frequencies in crossbred cattle with maximum likelihood. J. Dairy Sci. 74:2728-2736.

Bredbacka, P., and M. T. Koskinen. 1999. Microsatellite panels suggested for parentage testing in cattle: Informativeness revealed in Finnish Ayrshire and Holstein-Friesian populations. Agri. Food Sci. Finl. 8:233-237.

Christensen, L. G., P. Madsen, and J. Petersen. 1982. The influence of incorrect sire identification on the estimates of genetic parameters and breeding values. Pages 200-208 in Proc. 2nd World Cong. Genet. Appl. Livest. Prod., Madrid, Spain.

Crawford, A. M., and R. P. Cuthbertson. 1996. Mutations in sheep microsatellites. Genome Res. 6:876-879.

Geldermann, H., U. Pieper, and W. E. Weber. 1986. Effect of misidentification on the estimation of breeding value and heritability in cattle. J. Anim. Sci. 63:1759-1768.

Glowatzki-Mullis, M.-L., and J. Muntwyler. 2002. Reliability of DNA certificates in parentage verification for cattle. Page 98 in Proc. Int. Conf. Anim Genet., Gottingen, Germany.

Israel, C., and J. I. Weller. 2000. Effect of misidentification on genetic gain and estimation of breeding value in dairy cattle populations. J. Dairy Sci. 83:181-187.

Kappes, S. M., J. W. Keele, R. T. Stone, T. S. Sonstegard, T. P. L. Smith, R. A. McGraw, N. L. LopezCorrales, and C. W. Beattie. 1997. A second-generation linkage map of the bovine genome. Genome Res. 7:235-249.

Petersen, A. H., and C. Bendixen. 2000. Null-alleles in the standard set of loci for cattle parentage control. Page 89 in Proc. Int. Conf. Anim Genet., St. Paul, MN.

Riquet, J., W. Coppieters, N. Cambisano, J. J. Arranz, P. Berzi, S. K. Davis, B. Grisart, F. Farnir, L. Karim, M. Mni, P. Simon, J. F. Taylor, P. Vanmanshoven, D. Wagenaar, J. E. Womack, and M. Georges. 1999. Fine-mapping of quantitative trait loci by identity by descent in outbred populations: Application to milk production in dairy cattle. Proc. Natl. Acad. Sci. USA 96:9252-9257.

Ron, M., Y. Blank, M. Band, E. Ezra, and J. I. Weller. 1996. Misidentification rate in the Israeli dairy cattle population and its implications for genetic improvement. J. Dairy Sci. 79:676-681.

Ron, M., R. Domochovsky, M. Golik, E. Seroussi, E. Ezra, C. Shturman, and J. I. Weller. 2003. Analysis of vaginal swabs for paternity testing and marker-assisted selection in cattle. J. Dairy Sci. 86:1789-1796.

Ron, M., E. Feldmesser, M. Golik, I. Tager-Cohen, D. Kliger, V. Reiss, R. Domochovsky, O. Alus, E. Seroussi, E. Ezra, and J. I. Weller. 2004. A complete genome scan of the Israeli Holstein population for quantitative trait loci by a daughter design. J. Dairy Sci. 87:476-490. 
Stormont, C. 1967. Contribution of blood typing to dairy science progress. J. Dairy Sci. 50:253-260.

Van Vleck, L. D. 1970a. Misidentification in estimating the paternalsib correlation. J. Dairy Sci. 53:1469-1474.

Van Vleck, L. D. 1970b. Misidentification and sire evaluation. J. Dairy Sci. 53:1697-1702.

Visscher, P. M., J. A. Woolliams, D. Smith, and J. L. Williams. 2002. Estimation of pedigree errors in the UK dairy population using microsatellite markers and the impact on selection. J. Dairy Sci. 85:2368-2375.
Weller, J. I. 1994. Economic Aspects of Animal Breeding. Chapman \& Hall. London, UK.

Weller, J. I., and E. Ezra. 1997. Genetic analysis of somatic cell concentration and female fertility of Israeli Holsteins by the individual animal model. J. Dairy Sci. 80:586-593.

Weller, J. I., Y. Kashi, and M. Soller. 1990. Power of "daughter" and "granddaughter" designs for genetic mapping of quantitative traits in dairy cattle using genetic markers. J. Dairy Sci. 73:2525-2537. 